\title{
Medisch specialisten in de OOR Noord- \& Oost-Nederland steunen innovaties medische vervolgopleidingen
}

\author{
R.H. Bakker, A.K. Meininger, G.J. Dijkstra, S.A. Reijneveld, J.W. Groothoff
}

\begin{abstract}
Samenvatting
Inleiding: De medische vervolgopleidingen worden momenteel ingrijpend gemoderniseerd. Hierbij is sprake van een herontwerp van het huidige opleidingsplan naar een competentiegericht curriculum. In de Onderwijs- en Opleidingsregio (OOR) Noord- \& Oost-Nederland worden de opleidingsinnovaties regionaal gecoördineerd. Het doel van deze studie is antwoord te vinden op de vraag hoe er door medisch specialisten wordt gedacht over de innovaties van de medische vervolgopleidingen.

Methode: Onder alle medisch specialisten in de OOR Noord-\& Oost-Nederland is aan de hand van een vragenlijst onderzoek verricht dat gericht was op de betrokkenheid van medisch specialisten bij de medische vervolgopleidingen en innovaties, op het belang dat er aan modernisering van deze innovaties wordt gehecht en op de knelpunten die medisch specialisten voorzien bij de implementatie van de opleidingsinnovaties. Tevens is gevraagd naar de mening over enkele moderniseringsvoorstellen die - los van de opleidingsinnovatie van het Centraal College Medische Specialismen (CCMS) - zijn gedaan door een aantal wetenschappelijke verenigingen.

Resultaten: Nagenoeg 60\% van de medisch specialisten is bij de medische vervolgopleidingen betrokken, terwijl $20 \%$ bij de innovaties is betrokken. Bijna $90 \%$ van de specialisten is van oordeel dat de specialistenopleidingen gemoderniseerd dienen te worden. Er worden echter wel knelpunten bij de implementatie van de onderwijsvernieuwingen voorzien. Deze knelpunten liggen met name op het terrein van de bedrijfsvoering, de kwaliteit van de zorg en de kwaliteit van de opleiding.

Conclusies en beschouwing: Het draagvlak voor vernieuwing van de medische vervolgopleidingen binnen de OOR Noord- \& Oost-Nederland is groot te noemen. (Bakker RH, Meininger AK, Dijkstra GJ, Reijneveld SA, Groothoff JW. Medisch specialisten in de OOR Noord-\& Oost-Nederland steunen innovaties medische vervolgopleidingen. Tijdschrift voor Medisch Onderwijs 2008;27(3):129-136.)
\end{abstract}

\section{Inleiding}

Momenteel worden in opdracht van het Centraal College Medische Specialismen (CCMS) de medische vervolgopleidingen ingrijpend gemoderniseerd. De modernisering behelst met name een herontwerp van het huidige opleidingsplan naar een competentiegericht curriculum. ${ }^{1-3}$ Daarbij dient in het nieuwe curriculum expliciet aandacht te worden besteed aan de ontwikkeling en toetsing van nauw met het medisch handelen verweven competenties (samenwerking, organisatie, communicatie, evidence based medicine, maatschappelijk handelen en professionaliteit). Een hieraan inherente vernieuwing is dat de artsen in opleiding tot specialist (aios) zelf hun voortgang moeten bijhouden in een 
portfolio. Ook de reflectie over het eigen handelen wordt hierin weergegeven, evenals het resultaat van de verschillende beoordelingsmomenten die er tijdens de opleiding plaatsvinden.

Los van de CCMS-opleidingsmodernisering, maar wel passend binnen het medisch opleidingscontinuüm, is door enkele wetenschappelijke verenigingen een voorstel voor een 'common trunk' (een gemeenschappelijke basisvervolgopleiding voor verwante disciplines) gelanceerd. Daarnaast hebben enkele medische faculteiten c.q. UMC's een zogenaamd 'schakeljaar' ter verbetering van de aansluiting tussen de initiële opleidingen geneeskunde en de medische vervolgopleidingen voorgesteld.

In de Onderwijs- en Opleidingsregio (OOR) Noord- \& Oost-Nederland (bestaande uit de provincies Groningen, Friesland, Drenthe en Overijssel) wordt een en ander met betrekking tot de opleidingsinnovaties regionaal aangepakt, in nauwe samenwerking tussen het Universitair Medisch Centrum Groningen (UMCG) en de andere opleidingsziekenhuizen. Voor deze aanpak is het van belang kennis te verwerven over de vraag hoe er door medisch specialisten in de OOR Noord- \& Oost-Nederland wordt gedacht over de innovaties van de medische vervolgopleidingen. Aan de hand van een vragenlijst is onder alle medisch specialisten in de OOR Noord- \& Oost- Nederland een uitgebreid onderzoek verricht, met als belangrijke vragen:

- Wat is de betrokkenheid van medisch specialisten bij de medische vervolgop- leiding en bij de innovaties binnen deze opleiding?

- Welk belang hechten medisch specialisten aan de modernisering van de vervolgopleiding?

- Welke problemen voorzien medisch specialisten ten gevolge van de innovaties?

- Hoe denken medisch specialisten over enkele los van de CCMS-opleidingsmodernisering gelanceerde innovatievoorstellen, zoals common trunk en schakeljaar?

\section{Methode}

In de eerste helft van 2006 is naar 2146 personen, die te boek stonden als praktizerend medisch specialist in de regio Noord\& Oost-Nederland, een vragenlijst gestuurd. De vragenlijst is door 1132 specialisten ingevuld teruggestuurd, hetgeen neerkomt op een respons van 53\%. De respons van specialisten werkzaam binnen het UMCG was daarbij wat hoger, namelijk 59\%. De verdeling van de respondenten over de diverse specialismen sluit aan bij de landelijke verdeling, uitgezonderd een ondervertegenwoordiging van psychiaters $(4.1 \%, \mathrm{n}=44$, versus $15.2 \%$ landelijk) en internisten $(7 \%, \mathrm{n}=75$, versus $10 \%$ landelijk).

\section{Resultaten}

\section{Betrokkenheid bij de opleiding}

Nagenoeg $60 \%$ van de medisch specialisten blijkt op de één of andere manier bij de medische vervolgopleiding betrokken (zie tabel 1).

Tabel 1. Bent u in uw eigen ziekenhuis betrokken bij de opleiding tot medisch specialist?

\begin{tabular}{lrrrrrrr}
\hline & \multicolumn{3}{c}{ Man } & \multicolumn{2}{c}{ Vrouw } & \multicolumn{2}{c}{ Totaal } \\
\hline Ja & $\mathbf{n}$ & $\%$ & $\mathbf{n}$ & $\%$ & 651 & 59 \\
Nee & 514 & 58 & 137 & 62 & 454 & 41 \\
\hline Totaal & 370 & 42 & 84 & 38 & $\mathbf{1 1 0 5}$ & $\mathbf{1 0 0}$ \\
\hline
\end{tabular}


Vrouwelijke specialisten zijn relatief vaker actief betrokken als supervisor (47\% van de vrouwen versus $33 \%$ van de mannen). Opleiders zijn echter vrijwel altijd mannen. Van de $80 \%$ specialisten die in dienstverband werken blijken er procentueel aanmerkelijk meer bij de opleiding betrokken dan van de $20 \%$ zelfstandig werkende medisch specialisten (namelijk 85 versus $48 \%$ ). Dit ligt voor de hand gezien het feit dat verreweg het grootste deel van de medisch specialisten in dienstverband binnen het UMCG werkzaam is. Toch geeft ruim $47 \%$ van de medisch specialisten in de niet academische ziekenhuizen aan betrokken te zijn bij de opleiding.

Driekwart van alle deelnemende specialisten is op de hoogte van de veranderingen die binnen de vervolgopleidingen plaatsvinden (zie tabel 2). Ongeveer een op de negen medisch specialisten die bij de opleiding zijn betrokken blijkt desondanks niet op de hoogte te zijn van de veranderingen binnen de medische vervolgopleidingen. Bij de subgroep van medisch specialisten zonder betrokkenheid bij de opleiding ligt dit percentage aanmerkelijk hoger $(44 \%)$. Van de respondenten die op de hoogte zijn van de veranderingen binnen de medisch specialistische vervolgopleidingen weet echter ruim de helft niet of slechts vaag om welke competenties het daarbij gaat.

\section{Betrokkenheid bij de innovaties vervolgopleidingen}

Nagenoeg één op de vijf medisch specialisten $(19 \%)$ is actief bij de innovaties van de medische vervolgopleidingen betrokken, te weten $27 \%$ van de in dienstverband werkende specialisten versus 15\% van de zelfstandige specialisten.

\section{Mening over het belang van de modernisering van de opleidingen}

Bijna 90\% van de respondenten is van oordeel dat de specialistenopleidingen gemoderniseerd dienen te worden, zij het dat ruim een derde de mening is toegedaan dat dit 'enigszins' dient te gebeuren (zie tabel 3). Er blijkt dus ruime steun te bestaan voor het doorvoeren van innovaties. Leeftijd blijkt daarbij geen factor die in belangrijke mate van invloed is op die mening; de percentages van voor- en tegenstanders van modernisering van de opleidingen zijn over alle drie de leeftijdscategorieën globaal vergelijkbaar, met mogelijk iets meer terughoudendheid bij de oudere medisch specialisten (zie tabel 3).

\section{Het voorzien van knelpunten}

Op de vraag aan alle medisch specialisten of zij problemen voorzien bij de implementatie antwoordt nagenoeg $70 \%$ bevestigend (zie tabel 4). Meer medisch specialisten in dienstverband dan zelfstandig

Tabel 2. Op de hoogte van te verwachten veranderingen in vervolgopleidingen versus betrokkenheid bij de medische vervolgopleiding.

\begin{tabular}{|c|c|c|c|c|c|c|}
\hline \multicolumn{7}{|c|}{ Betrokken bij de opleiding? } \\
\hline \multicolumn{7}{|l|}{ Op de hoogte van } \\
\hline \multirow{2}{*}{$\begin{array}{l}\text { veranderingen } \\
\text { vervolgopleidingen? }\end{array}$} & \multicolumn{2}{|c|}{ Ja } & \multicolumn{2}{|c|}{ Nee } & \multicolumn{2}{|c|}{ Totaal } \\
\hline & $\mathbf{n}$ & $\%$ & n & $\%$ & $\mathrm{n}$ & $\%$ \\
\hline Ja & 575 & 89 & 253 & 56 & 828 & 75 \\
\hline Nee & 75 & 11 & 196 & 44 & 271 & 25 \\
\hline Totaal & 650 & 100 & 449 & 100 & 1099 & 100 \\
\hline
\end{tabular}


Tabel 3. Vindt $u$ het belangrijk dat de specialistenopleidingen gemoderniseerd worden (naar leeftijdscategorieën)?

\begin{tabular}{lrrrrrrrr}
\hline & \multicolumn{2}{c}{$25-39$} & \multicolumn{2}{c}{$40-54$} & \multicolumn{2}{c}{$55-65$} & \multicolumn{2}{c}{ Totaal } \\
& $\mathbf{n}$ & $\%$ & $\mathbf{n}$ & $\%$ & $\mathbf{n}$ & $\%$ & $\mathbf{n}$ & $\%$ \\
\hline Ja & 76 & 59 & 363 & 55 & 157 & 53 & 596 & 55 \\
Nee & 16 & 12 & 73 & 11 & 31 & 10 & 120 & 11 \\
Enigszins & 38 & 29 & 225 & 34 & 110 & 37 & 373 & 34 \\
\hline Totaal & 130 & 100 & $\mathbf{6 6 1}$ & $\mathbf{1 0 0}$ & $\mathbf{2 9 8}$ & $\mathbf{1 0 0}$ & $\mathbf{1 0 8 9}$ & $\mathbf{1 0}$ \\
\hline
\end{tabular}

Tabel 4. Het voorzien van problemen bij implementatie innovaties versus aard dienstverband.

\begin{tabular}{lrrrrrr} 
Voorziet u problemen & \multicolumn{2}{c}{ Dienstverband } & \multicolumn{2}{c}{ Zelfstandig } & \multicolumn{2}{c}{ Totaal } \\
bij innovaties? & $\mathbf{n}$ & $\%$ & $\mathbf{n}$ & $\%$ & $\mathbf{n}$ & $\%$ \\
\hline Ja & 234 & 75 & 441 & 65 & 675 & 68 \\
Nee & 78 & 25 & 235 & 35 & 313 & 32 \\
\hline Totaal & $\mathbf{3 1 2}$ & $\mathbf{1 0 0}$ & $\mathbf{6 7 6}$ & $\mathbf{1 0 0}$ & $\mathbf{9 8 8}$ & $\mathbf{1 0 0}$ \\
\hline
\end{tabular}

werkende medisch specialisten voorzien problemen (75 versus 65\%). Toetsing met een t-toets laat zien dat dit verschil significant is. Ook als deze analyse wordt verricht bij de subgroep medisch specialisten die op de hoogte zijn van de op handen zijnde veranderingen, blijft deze tendens zichtbaar, zij het minder duidelijk en niet significant (78 versus $72 \%$ ).

Problemen worden vooral voorzien binnen de bedrijfsvoering rond het implementatietraject (driekwart van de medisch specialisten). Ruim een derde van de respondenten geeft aan dat zij problemen voorzien ten aanzien van respectievelijk de kwaliteit van de zorg en de kwaliteit van de opleiding. Nagenoeg een kwart van de respondenten voorziet tevens problemen die op andere terreinen liggen, zoals de opleidingscapaciteit en financiële knelpunten. Andere zorgen van medisch specialisten zijn dat het doorvoeren van vernieuwingen te veel tijd gaat kosten $(63 \%)$, dat aios in het nieuwe opleidingssysteem te veel van de werkvloer zullen zijn (74\%), dat specialisten te weinig didactisch geschoold zijn om de innovaties door te kunnen voeren $(68 \%)$ en dat veranderingen in de bedrijfsvoering, alsmede cultuurveranderingen, nog niet zo snel doorgevoerd zullen zijn (respectievelijk 71 en 60\%).

\section{Emotionele betrokkenheid bij de opleiding en opleidingsinnovaties}

Medisch specialisten in de OOR Noord- \& Oost-Nederland blijken niet alleen feitelijk bij de innovaties van de medische vervolgopleidingen betrokken te zijn. Zij geven ook aan zich erbij betrokken te voelen en willen deze betrokkenheid graag verder gestalte geven. Zo blijkt dat nagenoeg een derde van de medisch specialisten een cursus heeft gevolgd op het gebied van docentprofessionalisering. Van de specialisten die een dergelijke cursus niet hebben gevolgd, zou 58\% graag een training willen volgen om beter te leren superviseren. Ruim de helft van alle deelnemende specialisten volgt in een wetenschappelijke vereniging de ontwikkelingen rond de op- 
leiding, terwijl 56\% van de nu nog niet bij de innovaties betrokkenen graag erbij betrokken zou willen zijn binnen het ziekenhuis waar zij werkzaam zijn. Bij regionale opleidingsinnovaties zou bijna de helft (46\% van de medisch specialisten) wel betrokken willen zijn.

\section{Het onderschrijven van centrale} elementen van de opleidingsinnovaties

Een meerderheid van de medisch specialisten in de OOR Noord- \& Oost-Nederland blijkt een aantal centrale elementen, waaruit de innovaties van de opleidingen bestaan, te ondersteunen (zie tabel 5). Ook blijkt $69 \%$ het in min of meerdere mate eens te zijn met het instellen van een schakeljaar en wordt het plan voor realisering van een common trunk door $67 \%$ onderschreven. De steun voor dit idee wordt nog eens extra onderstreept door het feit dat $84 \%$ van de respondenten van oordeel is dat disciplineoverstijgend onderwijs multidisciplinaire samenwerking bevordert: één van de redenen voor het instellen van een common trunk. Ook voor competentiegericht onderwijs blijkt steun te bestaan bij medisch specialisten. Niet minder dan $85 \%$ van de respondenten is van mening dat hierdoor de communicatie van artsen kan worden verbeterd, terwijl $82 \%$ vindt dat ook andere voor het beroep noodzakelijke competenties door dit type onderwijs kunnen worden ontwikkeld. De overgrote meerderheid van de medisch specialisten is dan ook gemotiveerd om mee te werken

Tabel 5. Mening medisch specialisten over centrale elementen opleidingsinnovatie (percentages).

\begin{tabular}{|c|c|c|c|c|c|}
\hline & $\begin{array}{l}\text { Helemaal } \\
\text { mee eens }\end{array}$ & $\begin{array}{l}\text { Enigszins } \\
\text { mee eens }\end{array}$ & $\begin{array}{c}\text { Enigszins } \\
\text { mee oneens }\end{array}$ & $\begin{array}{l}\text { Helemaal } \\
\text { mee oneens }\end{array}$ & $\mathrm{n}$ \\
\hline $\begin{array}{l}\text { Tijdens de klinische fase dient } \\
\text { via een schakeljaar al aansluiting } \\
\text { te worden gezocht bij de } \\
\text { medische vervolgopleidingen }\end{array}$ & 18 & 51 & 20 & 11 & 1090 \\
\hline $\begin{array}{l}\text { De eerste twee jaren van de vervolg- } \\
\text { opleiding lenen zich voor een } \\
\text { 'commun trunk' voor een groep } \\
\text { van specialismen }\end{array}$ & 19 & 48 & 20 & 13 & 1088 \\
\hline $\begin{array}{l}\text { Door in de opleiding meer aandacht } \\
\text { te geven aan discipline-overstijgend } \\
\text { onderwijs wordt multidisciplinaire } \\
\text { samenwerking bevorderd }\end{array}$ & 25 & 59 & 14 & 2 & 1089 \\
\hline $\begin{array}{l}\text { Door de competentie communicatie } \\
\text { in het curriculum in te bouwen leren } \\
\text { artsen beter te communiceren }\end{array}$ & 27 & 58 & 12 & 3 & 1085 \\
\hline $\begin{array}{l}\text { Door competentiegericht onderwijs } \\
\text { leert de arts niet alleen medische } \\
\text { kennis en vaardigheden, maar alle voor } \\
\text { het beroep noodzakelijke competenties }\end{array}$ & 20 & 62 & 15 & 3 & 1074 \\
\hline
\end{tabular}


aan vernieuwingen in de opleiding: $84 \%$ van alle respondenten.

\section{Conclusies en beschouwing}

In dit onderzoek is de betrokkenheid geïnventariseerd van medisch specialisten binnen de OOR Noord- \& Oost-Nederland bij de innovatie van de medische vervolgopleidingen. Tevens is informatie verkregen over het belang dat medisch specialisten hechten aan de modernisering van deze opleidingen en aan hun inschatting van het ontstaan van eventuele problemen ten gevolge van de innovaties. De resultaten van het onderzoek laten zien dat een groot aantal medisch specialisten werkzaamheden verricht ten behoeve van de specialistische vervolgopleiding: nagenoeg $60 \%$. Bij de innovatie van de eigen opleiding is een veel kleiner deel, namelijk 19\%, betrokken. Negen van de tien medisch specialisten kunnen als voorstanders van de huidige opleidingsinnovatie worden beschouwd. Dit kan als een opmerkelijk hoog percentage worden aangemerkt. Toch worden door driekwart van de medisch specialisten problemen voorzien bij de implementatie van de opleidingsinnovaties, vooral op het terrein van de bedrijfsvoering, de kwaliteit van de zorg en de kwaliteit van de opleiding. De emotionele betrokkenheid - de mate waarin medisch specialisten de innovaties van de medische vervolgopleiding een belangrijk punt van aandacht vinden dat hun bezig houdt en waar zij graag meer betrokken bij zouden willen zijn - is groot te noemen. Dit blijkt tevens uit het hoge percentage specialisten dat aangeeft aan de vernieuwingen mee te willen werken.

Wat betekenen deze gegevens voor het verder vormgeven van de medische vervolgopleidingen? Ten eerste blijkt er een groot draagvlak te bestaan voor de opleidingsinnovaties en ook de motivatie om eraan mee te werken is hoog. Hierdoor lijkt het mogelijk de opleidingsvernieuwingen 'in gezamenlijkheid' vorm te geven. De resultaten van dit onderzoek onderstrepen het belang van een gericht beleid om de door medisch specialisten voorziene knelpunten bij deze implementatie van de innovaties zoveel mogelijk het hoofd te bieden. Een mogelijkheid daarvoor is het uitvoeren van veranderprojecten, waarbij aanpassingen in de bedrijfsvoering, patiëntenzorg en opleiding hand in hand gaan en continu worden geëvalueerd.

Ten tweede valt op dat een ruime meerderheid van de respondenten het belang van het realiseren van een 'common trunk' en het instellen van een schakeljaar onderschrijft. Zodra de vernieuwing van de vervolgopleidingen is afgerond zou gekeken kunnen worden naar gemeenschappelijke componenten van alle vervolgopleidingen. Dat zou op termijn kunnen leiden tot bijvoorbeeld een gemeenschappelijk basispakket voor respectievelijk de snijdende, de beschouwende en de ondersteunende disciplines. Gedacht kan worden aan een herstructurering van de vervolgopleidingen, gericht op functies voor artsen die redelijk breed inzetbaar zijn. Het is van belang opleidingen en/of leerroutes te ontwikkelen, die gericht zijn op de voor de patiëntenzorg gewenste competenties en die inspelen op de gewenste loopbaanmogelijkheden voor basisartsen. Dit stelt ook in staat artsen te selecteren die bij uitstek geschikt zijn voor doorstroming naar een bepaalde specialistische vervolgopleiding. Dit werkt zowel efficiency- als kwaliteitsverhogend.

Tot besluit willen we kort ingaan op de representativiteit van de gegevens van dit onderzoek. Met uitzondering van psychiaters, en in veel mindere mate internisten, blijkt het om een representatieve steekproef te gaan. Dat betekent dat de gevonden resultaten niet in aanzienlijke mate vertekend kunnen zijn door verschillen in mening ten aanzien van de innovaties die 
eventueel tussen specialismen bestaan. Bij de vraag naar de representativiteit van de gegevens is ook van belang in hoeverre non-responders een andere mening zijn toegedaan dan specialisten die de vragenlijst wel hebben ingestuurd. Hiervan kan helaas geen inschatting worden gemaakt, omdat dit onderzoek niet voorzag in een non-responsanalyse.

Er is ten slotte geen reden aan te nemen dat de mening van specialisten in de regio Noord- \& Oost-Nederland ten aanzien van de innovaties aanmerkelijk afwijkt van die van specialisten in de rest van Nederland.

\section{Belangrijkste conclusies}

- Een hoog percentage, nagenoeg $60 \%$, van de medisch specialisten in de OOR Noord- \& Oost -Nederland is betrokken bij de medische vervolgopleiding.

- Driekwart van de regionale specialisten is ervan op de hoogte dat de medische vervolgopleidingen gemoderniseerd worden, de helft daarvan weet echter (nog) niet precies de inhoud ervan en welke competenties daarin een rol spelen.

- Negentig procent van alle regionale specialisten - in alle leeftijdcategorieën - acht de innovatie van de medische vervolgopleidingen van belang.

- Medisch specialisten in de OOR Noord- \& Oost-Nederland zijn zowel feitelijk als emotioneel bij de innovaties van de medische vervolgopleidingen betrokken en geven aan deze betrokkenheid verder gestalte te willen geven. Dit biedt een goede basis om vervolgopleidingen in gezamenlijkheid vorm te geven.

- Er wordt door medisch specialisten positief gedacht over innovaties, zoals het competentiegericht onderwijs en de door enkele verenigingen voorgestelde common trunk en het door enkele
UMC's/medische faculteiten gelanceerde schakeljaar.

- Driekwart van de specialisten voorziet problemen bij de implementatie, vooral in de bedrijfsvoering. Dit onderstreept het belang van een gericht beleid om de voor medisch specialisten voorziene knelpunten bij deze implementatie van de innovaties zoveel mogelijk het hoofd te bieden.

\section{Literatuur}

1. Meininger AK, Bakker PPM. Nieuwe tijden, nieuwe dokters. Competentiegericht opleiden. Tijdschrift voor Medisch Onderwijs, 26(5):220-7. [Modern times, modern doctors. Competencebased specialist training. Dutch Journal of Medical Education 2007;26(5):220-7].

2. Bakker PPM, Meininger AK. Ontwikkelen en implementeren van een competentiegericht curriculum: van schrijftafel naar praktijk. Tijdschrift voor Medisch Onderwijs; 26(6):272-8; [Development and implementation of a competence based curriculum: from writing table to practice. Dutch Journal of Medical Education 2007:26(6):272-8].

3. Bleker OP, Hoorntje JCA, Schelfhout VJ. Beter en leuker: CCMS ontvouwt plannen voor de vervolgopleiding van medisch specialisten. Med Contact 2004;59(43):1692-5. [CCMS present plans for postgraduate specialist training. Medical Contact 2004;59(43):1692-5].

De auteurs:

Dr. R.H. Bakker (Roel) is senioronderzoeker bij Toegepast Gezondheidsonderzoek (TGO) van het UMCG en is als hoofdonderzoeker bij het project betrokken geweest. Drs. A.K. Meininger (Abe) is onderwijskundige en werkzaam als hoofd Medische Vervolgopleidingen bij het Wenckebach Instituut van het UMCG en lid van de Begeleidingscommissie Beschrijving Opleidingsplannen Vervolgopleidingen (BBOV).

Mw. dr. G.J. Dijkstra (Geke) is coördinator van Toegepast Gezondheidsonderzoek (TGO) van het UMCG en is als mede-onderzoeker bij het project betrokken geweest. Prof. dr. S.A. Reijneveld (Menno) is hoogleraar Sociale Geneeskunde aan het UMCG en als supervisor bij het project betrokken geweest.

Prof. dr. J.W. Groothoff (Johan) is hoogleraar Arbeid en Gezondheid aan het UMCG en eveneens als supervisor bij het project betrokken geweest. 
Correspondentieadres:

Dr. R.H. Bakker, Toegepast Gezondheidsonderzoek

(TGO), UMCG, de Brug, A. Deusinglaan 1, 9713 AV

Groningen; e-mail: r.h.bakker@med.umcg.nl
Belangenconflict: geen gemeld.

Financiële ondersteuning: geen gemeld.

\section{Summary}

Introduction: Existing postgraduate specialist training programmes are being modernised and replaced by a competence-based curricula. In the Netherlands, the Northern \& Eastern regional training body coordinates the innovation of specialist training in their area. A study investigated specialists' perceptions of innovations in postgraduate medical training.

Method: A questionnaire survey among all medical specialists in the Northern \& Eastern region examined the respondents' involvement in postgraduate training and the innovations, their perceived importance of modernising postgraduate training and any problems they expected in implementing educational innovations. The specialists were also asked to give their opinion about several proposals for modernisation put forward by a number of scientific associations - other than the proposals of the Central College of Medical Specialties.

Results: Of the respondents, almost $60 \%$ were involved in postgraduate training and of these, $20 \%$ were involved in innovations. Almost $90 \%$ of the respondents thought that it was necessary to modernise postgraduate training programmes. Any expected problems were related to management, the quality of care and the quality of training programmes.

Conclusion: There appears to be broad support for modernising postgraduate specialist training in the Northern \& Eastern region of the Netherlands. (Bakker RH, Meininger AK, Dijkstra GJ, Reijneveld SA, Groothoff JW. Medical specialists in the Northern and Eastern region support innovations in postgraduate specialist training. Dutch Journal of Medical Education 2008;27(3):129-136.) 